\title{
Circulating microRNAs (miR-126, miR-197, and miR-223) are associated with chronic kidney disease among elderly survivors of the Great East Japan Earthquake
}

Ryosuke Fujii ${ }^{1}$, Hiroya Yamada ${ }^{2}$, Mirai Yamazaki ${ }^{3,4}$, Eiji Munetsuna ${ }^{5}$, Yoshitaka Ando ${ }^{3}$, Koji Ohashi ${ }^{3}$, Hiroaki Ishikawa ${ }^{3}$, Haruki Shimoda ${ }^{6}$, Kiyomi Sakata ${ }^{6}$, Akira Ogawa ${ }^{7}$, Seiichiro Kobayashi ${ }^{7}, K_{\text {Koji Suzuki }}{ }^{*}$ (D) and the RIAS study group

\begin{abstract}
Background: A recent study has reported that incidence of chronic kidney disease (CKD) is higher in evacuees, but the molecular mechanism still remains unclear. One plausible hypothesis is a change in vascular function following to psychological distress. In order to assess molecular mechanisms underlying this association, we examined whether cardiovascular disease (CVD)-associated miRNAs (miR-126, miR-197, and miR-223) were associated with CKD among Japanese elderly survivors after an earthquake.

Methods: We analyzed 1385 individuals (670 men and 715 women) who participated in a post-disaster health check-up after the Great East Japan Earthquake, which occurred in 2011. The check-up involved collection of information about lifestyle, clinical history, the degree of housing damage, and baseline measurement of the estimated glomerular filtration rate. Expression levels of miRNAs were determined using real-time polymerase chain reaction. Estimated glomerular filtration rate (eGFR) was calculated using sex, age, and serum creatinine. CKD was defined as eGFR $<60 \mathrm{ml} / \mathrm{min} / 1.73 \mathrm{~m}^{2}$. The multivariable regression analyses were performed to examine the associations between CVD-associated miRNAs and CKD after adjusting potential confounders.
\end{abstract}

Results: Mean age (standard deviation) of participants with normal kidney function and CKD was 62.7 (10.6) and 71.9 (8.1) years, respectively. Expression levels of these miRNAs in participants with CKD were significantly lower than normal kidney function (all $p<0.001$ ). Even after adjusting for lifestyle, clinical profiles, and psychological distress, significant associations between three miRNAs and CKD still remained. A significant linear association between the cumulative score of these miRNAs and CKD was found $(p=0.04)$.

Conclusions: This cross-sectional study suggested that CVD-associated miRNAs were an important factor of CKD in an elderly Japanese population after earthquake. Future studies need to examine this association in longitudinal dataset.

Keywords: Chronic kidney disease, microRNA, Cardiovascular disease, Molecular epidemiology, Population-based study

\footnotetext{
* Correspondence: ksuzuki@fujita-hu.ac.jp

${ }^{1}$ Department of Preventive Medical Sciences, Fujita Health University School of Medical Sciences, 1-98 Dengakugakubo, Kutsukake-cho, Toyoake 470-1192, Japan

Full list of author information is available at the end of the article
}

(C) The Author(s). 2019 Open Access This article is distributed under the terms of the Creative Commons Attribution 4.0 International License (http://creativecommons.org/licenses/by/4.0/), which permits unrestricted use, distribution, and reproduction in any medium, provided you give appropriate credit to the original author(s) and the source, provide a link to the Creative Commons license, and indicate if changes were made. The Creative Commons Public Domain Dedication waiver (http://creativecommons.org/publicdomain/zero/1.0/) applies to the data made available in this article, unless otherwise stated. 


\section{Background}

Chronic kidney disease (CKD) has become a public health issue in Japan, similar to other developed countries around the world $[1,2]$. The number of patients with an estimated glomerular filtration rate (eGFR) less than 60 $\mathrm{mL} / \mathrm{min} / 1.73 \mathrm{~m}^{2}$ in Japan has reached approximately 13 millions [3]. CKD is associated with cardiovascular disease (CVD) as a major complication [4]. Conversely, CVD is also a risk factor for CKD, which may be mediated by the development of atherosclerosis with vascular calcification and endothelium dysfunction [5].

MicroRNAs (miRNAs), small non-coding RNAs with a length of 18-25 nucleotides, are present as many forms in blood. The biological function of miRNAs is to bind to the 3 '-untranslated region of the target mRNAs and thus regulate gene expression $[6,7]$. miRNAs have been investigated in various pathophysiological conditions $[8,9]$ and diseases, including cancer [10-14], CVD [15, 16], diabetes [17], liver disease [18, 19], kidney disease [20], and autoimmune disease [21, 22]. In particular, numerous clinical studies have investigated the associations between CKD and miRNAs in patients and experimental animals [23-28].

A recent prospective study has reported the incidence rate of CKD was higher in evacuees after the Great East Japan Earthquake, a large earthquake occurred in Japan [29]. They speculated that psychological distress after disaster can induce metabolic disorder and hypertension, which lead to kidney dysfunction. However, possible biological mechanisms underlying this association still remain unclear.

Therefore, we focused on vascular function following to psychological distress in the development of CKD, and hypothesized that alterations in levels of vascular functionassociated miRNAs [30, 31] may be useful biomarkers for CKD among survivors. Here we investigated whether three circulating CVD-associated miRNAs (miR-126, miR-197, and miR-223) were associated with CKD among elderly survivors of the Great East Japan Earthquake.

\section{Methods}

\section{Study subjects}

The present study was nested within the Research Project for Prospective Investigation of Health Problems Among Survivors of the Great East Japan Earthquake and Tsunami Disaster (RIAS), a longitudinal study performed in the devastated areas in Japan. The RIAS study has been described previously [32]. The primary purpose was to screen the physical and psychological status of the residents in the devastated area after the Great East Japan Earthquake, which occurred in 2011, and to determine long-term effects of the disaster on individual health conditions among adults (over 18 years old) [3335]. The survey was conducted between September 2011 and February 2012, approximately 6 months after the disaster, in four municipalities (Yamada Town, Otsuchi
Town, Kamaishi City and Rikuzentakata City), which are areas that were heavily damaged by the earthquake and tsunami, and in Iwate Prefecture, which is located in the northern part of Japan. We sent out notifications to request a health check examination and a questionnaire to residents in Yamada Town, Otsuchi Town, and Rikuzentakata City ( $n=12,772,11,411$, and 18,648 , respectively). Kamaishi City was excluded in this study because we sent out notifications to residents of temporary housing. In Otsuchi Town, 2172 residents underwent the health examination (participation rate, 19.3\%). Of these residents, a total of 2085 individuals participated in the RIAS study (acceptance rate, 96.0\%). Among participants in Otsuchi Town $(n=2055), 670$ participants were excluded for the following reasons: those aged 40 years or younger $(n=212)$; missing value or indeterminable response in the items assessing the degree of housing damage, relocation experience, living environment, psychological factors, smoking status, and habitual alcohol consumption $(n=194)$; past clinical history of cancer, CVD (myocardial infarction, angina, or stroke), kidney disease, or artificial dialysis $(n=244)$; and those with unsuccessful miRNA measurement $(n=20)$. Consequently, a total of 1385 residents (495 men and 890 women) were included in our analysis. Written informed consent was obtained from all participants of this study. This study was approved by the Institutional Review Board of Iwate Medical University (No. H23-69) and the Ethics Review Committee at Fujita Health University (No. HM16-404).

\section{Definition of CKD}

Fasting serum samples were collected from all participants, and centrifuged within an hour of sampling. Biochemical assays were performed using an automated analyzer. eGFR was calculated according to the equation proposed by the Japanese Society of Nephrology: eGFR $=194 \times$ serum creatinine $^{-1.094} \times$ age $^{-0.287}(\times 0.739$ for women $)$ [36]. This equation was normally used in epidemiological studies. Individuals with eGFR $<60 \mathrm{~mL} / \mathrm{min} / 1.73 \mathrm{~m}^{2}$ (CKD stage $3-5$ ) were defined as having CKD.

\section{Measurement of microRNAs}

Quantitative real-time polymerase chain reaction (qRTPCR) was used to detect expression levels of three circulating CVD-associated miRNAs (miR-126, miR-197, and miR-223) in sera; this procedure has been described in detail elsewhere [18, 37]. Serum miRNAs were isolated using TRIzol reagent (Invitrogen, USA) according to the manufacturer's instructions. qRT-PCR was performed using the ABI PRISM 7900 Sequence Detection System (Applied Biosystems, Foster City, CA). Relative expression of miRNAs was calculated using the comparative cycle threshold (CT) method $\left(2^{-\Delta \Delta C T}\right)$. The RNA samples were spiked with C. elegans miR-39 (cel-mir-39) as 
an external control to check extraction of RNA and the efficacy of cDNA synthesis. This is a widely used and practical method for the measurement of circulating miRNAs $[38,39]$.

\section{Covariates}

Blood pressure was measured twice on both arms using an automatic sphygmomanometer after $5 \mathrm{~min}$ of rest. The average value of two readings was calculated and used in our analysis. Anthropometric measurements of height and weight were performed to calculate the body mass index (BMI, $\mathrm{kg} / \mathrm{m}^{2}$ ) during the health check-up. Fasting blood glucose levels were determined using an automated analyzer. We collected participants' information on demographic characteristics (age and sex), lifestyle (smoking status and alcohol consumption), housing environment after the earthquake and tsunami (relocation frequency, degree of housing damage, and current housing environment), and psychological condition (Kessler's scale) from a self-administered questionnaire. Details of these items in our questionnaire are shown in Additional file 1: Table S1.

\section{Statistical analysis}

The Student's t-test was used to compare three miRNA expression levels between the group with normal kidney function and the CKD group. In our regression analysis, all participants were divided into tertiles (low, middle, and high) according to the expression levels of each circulating miRNA. The multivariable logistic regression model was used to estimate the odds ratios (ORs) and 95\% confidence intervals (CIs) for CKD using the lowest tertile as a reference group. To examine the cumulative effect of these miRNAs on CKD, a miRNA score was calculated by summing the number of the highest tertile of each miRNA; the range was 0 to 3 . We then performed logistic regression analysis to estimate the ORs and 95\% CIs for the risk of CKD associated with miRNA score increments. These regression analyses were performed after adjusting for covariates, such as age, sex, blood glucose, BMI, systolic blood pressure, smoking status, alcohol consumption, relocation frequency, degree of housing damage, current housing environment, and psychological condition. Statistical significance was defined as a $p$-value less than 0.05 , and all tests were two-sided. All statistical analyses were performed using $\mathrm{R}$ version 3.5.1 statistical software ( $\mathrm{R}$ Foundation, Vienna, Austria).

\section{Results}

\section{Characteristics of participants}

Table 1 shows the basic characteristics of participants stratified by CKD status. Mean ages (standard deviations) of participants with normal kidney function and CKD were 62.7 (10.6) and 71.9 (8.1) years, respectively. The values of BMI, systolic blood pressure, blood glucose, and high-
Table 1 Basic characteristics of study subjects according to kidney function

\begin{tabular}{|c|c|c|}
\hline & $\begin{array}{l}\text { normal kidney } \\
\text { function }(n=1156)\end{array}$ & CKD $(n=229)$ \\
\hline Age (year) & $62.7(10.6)$ & $71.9(8.1)$ \\
\hline Male $(n, \%)$ & $402(34.8 \%)$ & $93(40.6 \%)$ \\
\hline Body mass index $\left(\mathrm{kg} / \mathrm{m}^{2}\right)$ & $24.1(3.5)$ & $24.6(3.1)$ \\
\hline Systolic blood pressure (mmHg) & $130.4(19.2)$ & $134.0(19.7)$ \\
\hline Diastolic blood pressure (mmHg) & $76.8(11.2)$ & $76.1(10.7)$ \\
\hline Blood glucose (mmol/l) & $6.28(2.19)$ & $6.58(2.02)$ \\
\hline Triglycerides $(\mathrm{mmol} /)^{\mathrm{a}}$ & $1.33[0.96,1.85]$ & $1.45[0.96,1.95]$ \\
\hline HDL-cholesterol (mmol/l) & $1.69(0.21)$ & $1.60(0.44)$ \\
\hline eGFR (mL/min per $\left.1.73 \mathrm{~m}^{2}\right)$ & $79.8(13.7)$ & $52.1(7.0)$ \\
\hline $\log (\operatorname{miR}-126)^{b}$ & $5.04(1.04)$ & $4.73(1.05)$ \\
\hline $\log (\operatorname{miR}-197)^{b}$ & $2.18(1.01)$ & $1.81(0.94)$ \\
\hline \multirow[t]{2}{*}{$\log (\operatorname{miR}-223)^{b}$} & $6.17(1.20)$ & $5.71(1.08)$ \\
\hline & n (\%) & n (\%) \\
\hline \multicolumn{3}{|l|}{ Smoking status } \\
\hline Never & $828(71.6 \%)$ & $180(78.6 \%)$ \\
\hline Ever & $128(11.1 \%)$ & $27(11.8 \%)$ \\
\hline Current & $200(17.3 \%)$ & $22(9.6 \%)$ \\
\hline \multicolumn{3}{|l|}{ Alcohol consumption } \\
\hline Never & $762(65.9 \%)$ & $158(69.0 \%)$ \\
\hline Ever & $160(13.8 \%)$ & $28(12.2 \%)$ \\
\hline Current & $234(20.2 \%)$ & $22(9.6 \%)$ \\
\hline \multicolumn{3}{|l|}{ Relocation experience } \\
\hline None & $427(36.9 \%)$ & $86(37.6 \%)$ \\
\hline$>1$ time & $729(63.1 \%)$ & $143(62.4 \%)$ \\
\hline \multicolumn{3}{|l|}{ Degree of housing damage } \\
\hline None & 426 (36.9\%) & $86(37.6 \%)$ \\
\hline$>$ Partially destroyed & $730(63.1 \%)$ & $143(62.4 \%)$ \\
\hline \multicolumn{3}{|l|}{ Living in a shelter } \\
\hline Yes & $512(44.3 \%)$ & $95(41.5 \%)$ \\
\hline \multicolumn{3}{|l|}{ Psychological distress (K6 > 13) } \\
\hline Yes & $75(6.5 \%)$ & $12(5.2 \%)$ \\
\hline
\end{tabular}

CKD Chronic kidney disease, eGFR Estimated glomerular filtration rate ${ }^{a}$ Expressed as median and interquartile range

${ }^{\mathrm{b}}$ Expressed as arbitrary scale

density lipoprotein-cholesterol in participants with normal kidney function were significantly different from those values in the CKD group $(p=0.02,0.01,0.05$, and 0.008 , respectively).

Associations between three circulating miRNAs and CKD The associations between three circulating miRNAs (miR-126, miR-197, and miR-223) and CKD status are shown in Fig. 1. Expression levels of all three miRNAs were significantly lower in the CKD group compared with the normal kidney function group (all $p<0.001$ ). 

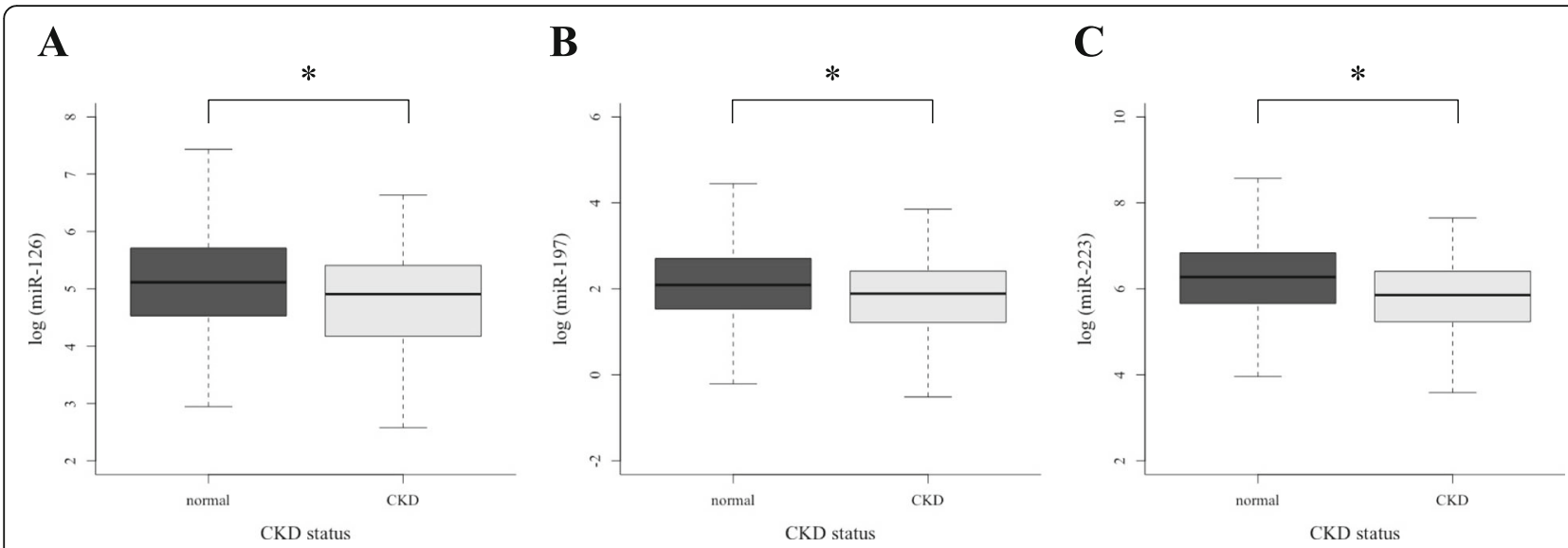

Fig. 1 The comparison of three circulating CVD-associated micro RNAs (miR-126, miR-197, and miR-223) between normal and CKD group

Table 2 shows crude and adjusted ORs with 95\% CIs for the risk of CKD according to different tertiles of each miRNA. Individuals in the highest tertile of each miRNA had a significantly lower risk for CKD compared with the lowest tertile of the miRNA (OR $[95 \% \mathrm{CI}]=0.67$ [0.45-0.98], 0.67 [0.46-0.99], and 0.53 [0.35-0.79], for miR-126, miR-197, and miR-223, respectively).

\section{Associations between miRNA score and CKD}

Table 3 shows adjusted ORs with 95\% CIs for the risk of CKD according to different miRNA scores. The logistic regression model indicated that participants with the highest score (score: 3 ), which integrated the three miRNAs, had significantly lower ORs for CKD (eGFR <60) compared with the lowest score (score: 0) $(\mathrm{OR}[95 \% \mathrm{CI}]=0.46$ [0.26-0.79]), but no significant risk reduction in other scores (score: 1 and 2) was found ( $p=0.92$ and 0.83 ). An additional analysis confirmed the significant linearity in ORs for CKD according to the miRNA score $(p=0.04)$.

\section{Discussion}

The present study showed that three vascular functionassociated miRNAs (miR-126, miR-197, and miR-223) were significantly associated with CKD among survivors of the earthquake. This result suggested that difference in vascular function after the natural disaster might be an important factor of a lower kidney function. Our findings were consistent with the result observed in the case-control study in Belgium [28].

miR-126 is one of the most abundantly expressed miRNAs in endothelial cells (ECs), and is a well-studied miRNA in vascular biology and diseases [40, 41]. Fish et al. suggested that endogenous miR-126 may be associated with various vascular functions (angiogenesis, leukocyte adhesion, and inflammation) in atherosclerotic lesions by down-regulating expression of proteins involved in signaling pathways such as Sprouty-related enabled/ VASP homology domain-containing protein 1 and phosphatidyl inositol 3-kinase regulatory beta [42]. In their discussion, decreases in these molecules activate rapidly

Table 2 Associations between tertiles of three microRNAs and chronic kidney disease $(\mathrm{eGFR}<60)$

\begin{tabular}{|c|c|c|c|c|c|c|}
\hline \multirow[b]{2}{*}{ microRNA } & & \multirow[b]{2}{*}{ CKD (\%) } & \multicolumn{2}{|l|}{ Crude model } & \multicolumn{2}{|c|}{ Fully adjusted model } \\
\hline & & & OR $(95 \% \mathrm{Cl})$ & $p$ & OR $(95 \% \mathrm{Cl})$ & $p$ \\
\hline \multirow[t]{3}{*}{ miR-126 } & Low $(n=457)$ & $98(21.4 \%)$ & Reference & & Reference & \\
\hline & Middle $(n=471)$ & $76(16.1 \%)$ & $0.71(0.51-0.98)$ & 0.04 & $0.74(0.52-1.06)$ & 0.11 \\
\hline & High $(n=457)$ & $55(12.0 \%)$ & $0.50(0.35-0.72)$ & $<0.001$ & $0.67(0.45-0.98)$ & 0.04 \\
\hline \multirow[t]{3}{*}{ miR-197 } & Low $(n=457)$ & $100(21.9 \%)$ & Reference & & Reference & \\
\hline & Middle $(n=471)$ & 75 (15.9\%) & $0.68(0.48-0.94)$ & 0.02 & $0.72(0.50-1.02)$ & 0.07 \\
\hline & High $(n=457)$ & $54(11.8 \%)$ & $0.48(0.33-0.68)$ & $<0.001$ & $0.67(0.46-0.99)$ & 0.05 \\
\hline \multirow[t]{3}{*}{ miR-223 } & Low $(n=457)$ & $110(24.1 \%)$ & Reference & & Reference & \\
\hline & Middle $(n=471)$ & 75 (15.9\%) & $0.59(0.43-0.83)$ & 0.002 & 0.69 (0.49-0.98) & 0.04 \\
\hline & High $(n=457)$ & $44(9.6 \%)$ & $0.34(0.23-0.49)$ & $<0.001$ & $0.53(0.35-0.79)$ & 0.002 \\
\hline
\end{tabular}

eGFR Estimated glomerular filtration rate, CKD Chronic kidney disease, OR Odds ratio, 95\% Cl 95\% confidential interval

Adjustment for sex, age, blood glucose levels, systolic blood pressure, body mass index, smoking status, alcohol consumption, psychological distress, relocating experience, degree of housing damage, and living in a shelter 
Table 3 Association between cumulative score of three miRNAs and chronic kidney disease $(e G F R<60)$

\begin{tabular}{llll}
\hline microRNA score $(\mathrm{n})$ & OR $(95 \% \mathrm{Cl})$ & $p$ & trend $p$ \\
\hline $0(n=715)$ & Reference & & 0.04 \\
$1(n=216)$ & $1.02(0.66-1.56)$ & 0.19 & \\
$2(n=207)$ & $1.05(0.66-1.63)$ & 0.92 & \\
$3(n=247)$ & $0.46(0.26-0.79)$ & 0.007 & \\
\hline
\end{tabular}

eGFR Estimated glomerular filtration rate, OR Odds ratio, 95\% Cl 95\% confidential interval

Adjustment for sex, age, blood glucose levels, systolic blood pressure, body mass index, smoking status, alcohol consumption, psychological distress, relocating experience, degree of housing damage, and living in a shelter

accelerated fibrosarcoma in the mitogen-activated protein kinase signaling pathway, thus increasing expression of vascular endothelial growth factor and promoting angiogenesis. In addition to angiogenesis, Harris et al. found that increasing miR-126 levels in ECs inhibits vascular cell adhesion molecule 1 expression, resulting in decreased leukocyte adhesion to ECs [43]. Moreover, miR-126 increases sirtuin 1 and superoxide dismutase- 2 expression, thus decreasing oxidative stress in ECs [44]. Accordingly, higher levels of circulating miR-126 may be correlated with maintenance of vascular function and a reduced risk of CKD.

Our results showed a negative association between miR223 and eGFR. miR-223 is originally identified as an important regulator of hematopoietic system and is associated with various biological function and development of cancer, inflammatory diseases, and diabetes [45]. A recent paper using rats suggested that inhibition of miR-223 in injured carotid could be a therapeutic method to prevent vascular calcification [46]. On the other hand, another experimental study demonstrated that serum miR-223 is lower in ApoE knock-out mice, which show vascular calcification, than in wild-type counterparts [47]. This study also showed that expression levels of miR-223 in serum were opposite of the levels in tissue samples. As shown in the miRDB (http://mirdb.org/), miR-223 targets insulinlike growth factor 1 receptor (IGF-1R), and overexpression of miR-223 in plaque vascular smooth muscle cells (VSMCs) induces a decrease in IGF-1R [48]. Many researchers have demonstrated that increased expression of IGF-1R in VSMCs prevents cell proliferation and migration, a crucial and primary pathophysiological process in the atherosclerotic cascade $[48,49]$. Considering these previous studies, decreased expression levels of circulating miR-223 may be associated with increased expression of miR-223 in VSMCs, leading to protective effects against the atherosclerotic process.

miR-197 has been extensively studied in the field of cancer biology, including aspects such as apoptosis, proliferation, and metastasis [50-52]. We found that higher levels of circulating miR-197 were significantly associated with better kidney function. This result must be interpreted cautiously because other previous studies have shown a different relationship between miR-197 and CVD [30, 31]. Even though they did not provide clear explanations, one plausible mechanism is that miR-197, which is highly expressed in platelets, activates platelets and plays a role in the development of CVD [53]. However, the function of this miRNA in platelets is not fully understood. Further studies are needed to elucidate the function of miR-197 in human platelets, which can lead to biological mechanisms underlying the true relationship between miR197 and CKD.

The major finding in this study is the significant association between three circulating CVD-associated miRNAs and CKD among survivors after the earthquake. However, the present study also has some limitations. First, the design of this study was cross-sectional, which does not allow us to assess a possible causal relationship between CVD-associated miRNAs and CKD. Further studies with a longitudinal dataset may allow examination of a causal relationship between CVD-associated miRNAs and CKD. Second, our subjects were homogeneous in terms of ethnicity, age, and regional features. Accordingly, these results must be confirmed in other populations with different ethnicities, environmental factors, dietary habits, and lifestyles.

\section{Conclusion}

In summary, this study may provide a novel insight that CVD-associated circulating miRNAs were significantly associated with eGFR among survivors after the earthquake and tsunami disaster. These associations indicate that difference of CVD-associated miRNAs can contribute to a lower kidney function following to natural disaster. Further longitudinal studies in other populations are expected to assess this association among adults after natural disaster.

\section{Supplementary information}

Supplementary information accompanies this paper at https://doi.org/10. 1186/s12882-019-1651-0.

Additional file 1: Table S1. Details of the self-administered questionnaire used in this study.

\section{Abbreviations}

Cl: Confidential interval; CKD: Chronic kidney disease; CVD: Cardiovascular disease; EC: Endothelial cell; eGFR: Estimated glomerular filtration rate; IGF1R: Insulin-like growth factor-1 receptor; miRNA: microRNA; OR: Odds ratio; PCR: Polymerase chain reaction; RIAS: Research Project for Prospective Investigation of Health Problems Among Survivors of the Great East Japan Earthquake and Tsunami Disaster; VSMC: Vascular smooth muscle cell

\section{Acknowledgments}

The authors would like to thank the residents for their participation and the staff at the health check-up sties for their support. We are also grateful to Mr. 
Genki Mizuno, Mr. Yoshiki Tsuboi, Mr. Yuji Hattori, Ms. Chiharu Hagiwara, Mr. Daiki Shimodaira, and Ms. Nao Sadamoto for their technical assistance.

\section{Authors' contributions}

KSakata, AO, and SK designed this study; RF wrote the manuscript and performed statistical analysis; HS, KSakata, and RIAS study staff collected and managed clinical information from the health check-up; KSuzuki, HY, EM, MY, $\mathrm{KO}, \mathrm{HI}$, and YA performed the experiment; $\mathrm{HS}$ and KSakata helped supervise the field activities and conduct the literature review. All authors reviewed the manuscript and approved the final version.

\section{Funding}

This study was supported by a Grant-in-Aid from the Ministry of Health, Labour and Welfare, Health and Labour Sciences Research Grants, Japan (H23-Tokubetsu-Shitei-002; H24-Kenki-Shitei-001, H25-Kenki-Shitei-001). The role of the funding body is mainly in the study design of the Research Project for Prospective Investigation of Health Problems Among Survivors of the Great East Japan Earthquake and data collection.

\section{Availability of data and materials}

The datasets used and/or analyzed during the current study are available from the corresponding author on reasonable request.

\section{Ethics approval and consent to participate}

This study was approved by the Institutional Review Board of Iwate Medical University (No. H23-69) and the Ethics Review Committee at Fujita Health University (No. HM16-404). Written informed consent was obtained from all participants of this study.

\section{Consent for publication}

Not applicable.

\section{Competing interests}

The authors declare that they have no competing interests.

\section{Author details}

'Department of Preventive Medical Sciences, Fujita Health University School of Medical Sciences, 1-98 Dengakugakubo, Kutsukake-cho, Toyoake 470-1192, Japan. 'Department of Hygiene, Fujita Health University School of Medicine, 1-98 Dengakugakubo, Kutsukake-cho, Toyoake 470-1192, Japan. ${ }^{3}$ Department of Clinical Biochemistry, Fujita Health University School of Medical Sciences, 1-98 Dengakugakubo, Kutsukake-cho, Toyoake 470-1192, Japan. ${ }^{4}$ Department of Medical Technology, Kagawa Prefectural University of Health Sciences, 281-1 Hara, Mure-cho, Takamatsu 761-0123, Japan. ${ }^{5}$ Department of Biochemistry, Fujita Health University School of Medicine, 1-98 Dengakugakubo, Kutsukake-cho, Toyoake 470-1192, Japan. ${ }^{6}$ Department of Hygiene and Preventive Medicine, Iwate Medical University, 1-1-1 Idaidori, Yahaba-cho, Shiwa-gun, Iwate 028-3694, Japan. 'Iwate Medical University, 1-1-1 Idaidori, Yahaba-cho, Shiwa-gun, Iwate 028-3694, Japan.

Received: 13 September 2019 Accepted: 29 November 2019 Published online: 21 December 2019

\section{References}

1. Imai E, Horio M, Watanabe T, Iseki K, Yamagata K, Hara S, et al. Prevalence of chronic kidney disease in the Japanese general population. Clin Exp Nephrol. 2009;13:621-30

2. Murphy D, McCulloch CE, Lin F, Banerjee T, Bragg-Gresham JL, Eberhardt MS, et al. Prevalence of chronic kidney disease in the United States. Ann Intern Med. 2016;165:473-81.

3. Japan Nephrology Society. Special issue: Clinical practice guidebook for diagnosis and treatment of chronic kidney disease 2012. Nihon Jinzo Gakkai Shi. 2012;54:1034-191.

4. Chronic Kidney Disease Prognosis Consortium, Matsushita K, van der Velde M, Astor BC, Woodward M, Levey AS, de Jong PE, et al. Association of estimated glomerular filtration rate and albuminuria with all-cause and cardiovascular mortality in general population cohorts: a collaborative metaanalysis. Lancet. 2010;375:2073-81.

5. Menon V, Gul A, Sarnak MJ. Cardiovascular risk factors in chronic kidney disease. Kidney Int. 2005;68:1413-8.
6. Bartel DP. MicroRNAs: genomics, biogenesis, mechanism, and function. Cell. 2004;116:281-97.

7. Wang F, Chen C, Wang D. Circulating microRNAs in cardiovascular disease: from biomarkers to therapeutic targets. Front Med. 2014;8:404-18.

8. Munetsuna E, Yamada $H$, Ando $Y$, Yamazaki M, Tsuboi $Y$, Kondo M, et al. Association of subcutaneous and visceral fat with circulating microRNAs in a middle-aged Japanese population. Ann Clin Biochem. 2018;55:437-45.

9. Kondo M, Yamada H, Munetsuna E, Yamazaki M, Hatta T, Iwahara A, et al. Associations of serum microRNA-20a, $-27 \mathrm{a}$, and -103a with cognitive function in a Japanese population: the Yakumo study. Arch Gerontol Geriatr. 2019;82:155-60

10. Iorio MV, Croce CM. MicroRNAs in cancer: small molecules with a huge impact. J Clin Oncol. 2009;27:5848-56.

11. Jansson MD, Lund AH. MicroRNA and cancer. Mol Oncol. 2012;6:590-610.

12. Peng $Y$, Croce $C M$. The role of MicroRNAs in human cancer. Signal Transduct Target Ther. 2016;1:15004.

13. Price C, Chen J. MicroRNAs in cancer biology and therapy: current status and perspectives. Genes Dis. 2014;1(1):53-63.

14. Kong YW, Ferland-McCollough D, Jackson TJ, Bushell M. microRNAs in cancer management. Lancet Oncol. 2012;13:e249-58.

15. Thum T, Catalucci D, Bauersachs J. MicroRNAs: novel regulators in cardiac development and disease. Cardiovascular Dis. 2008;79:562-70.

16. Latronico MV, Catalucci D, Condorelli G. Emerging role of microRNAs in cardiovascular biology. Circ Res. 2007:101:1225-36.

17. He Y, Ding Y, Liang B, Lin J, Kim TK, Yu H, et al. A systematic study of dysregulated microRNA in type 2 diabetes mellitus. Int J Mol Sci. 2017;18:E456.

18. Yamada H, Suzuki K, Ichino N, Ando Y, Sawada A, Osakabe K, et al. Associations between circulating microRNAs (miR-21, miR-34a, miR-122 and miR-451) and non-alcoholic fatty liver. Clin Chim Acta. 2013;424:99-103.

19. Yamada H, Ohashi K, Suzuki K, Munetsuna E, Ando Y, Yamazaki M, et al. Longitudinal study of circulating miR-122 in a rat model of non-alcoholic liver disease. Clin Chim Acta. 2015;446:267-71.

20. Chandrasekaran K, Karolina DS, Sepramaniam S, Armugam A, Wintour EM, Bertram JF, et al. Role of microRNAs in kidney homeostasis and disease. Kidney Int. 2012:81:617-27.

21. Yamada H, Itoh M, Hiratsuka I, Hashimoto S. Circulating microRNAs in autoimmune thyroid diseases. Clin Endcrinol. 2014;81:276-81.

22. Hiratsuka I, Yamada H, Munetsuna E, Hashimoto S, Itoh M. Circulating microRNAs in graves' disease in relation to clinical activity. Thyroid. 2016;26:1431-40.

23. Glowacki F, Savary G, Gnemmi V, Buob D, Van der Hauwaert C, Lo-Guidice $J M$, et al. Increased circulating miR-21 levels are associated with kidney fibrosis. PLoS One. 2013;8:e58014

24. Neal CS, Michael MZ, Pimlott LK, Yong TY, Li JY, Gleadle JM. Circulating microRNA expression is reduced in chronic kidney disease. Nephrol Dial Transplant. 2011;26:3794-802.

25. Wang G, Kwan BC, Lai FM, Chow KM, Li PK, Szeto CC. Elevated levels of miR-146a and miR-155 in kidney biopsy and urine from patients with IgA nephropathy. Dis Markers. 2011;30:171-9.

26. Zarjou A, Yang S, Abraham E, Agarwal A, Liu G. Identification of a microRNA signature in renal fibrosis: role of miR-21. Am J Physiol Renal Physiol. 2011; 301:F793-801.

27. Zhou H, Hasni SA, Perez P, Tandon M, Jang SI, Zheng C, et al. miR-150 promotes renal fibrosis in lupus nephritis by downregulating SOCS1. J Am Soc Nephrol. 2013:24:1073-87.

28. Fourdinier $\mathrm{O}$, Schepers E, Metzinger-Le Meuth V, Glorieux G, Liabeuf S, Verbeke $F$, et al. Serum levels of miR-126 and miR-223 and outcomes in chronic kidney disease patients. Sci Rep. 2019;9:4477.

29. Hayashi $Y$, Nagai M, Ohira T, Satoh H, Sakai A, Ohtsuru A, et al. The impact of evacuation on the incidence of chronic kidney disease after the Great East Japan Earthquake: The Fukushima Health Management Survey. Clin Exp Nephrol. 2017;21:995-1002.

30. Schulte C, Molz S, Appelbaum S, Karakas M, Ojeda F, Lau DM, et al. miRNA197 and miRNA-223 predict cardiovascular death in a cohort of patients with symptomatic coronary artery disease. PLoS One. 2015;10:e0145930.

31. Zampetaki A, Willeit P, Tilling L, Drozdov I, Prokopi M, Renard JM, et al. Prospective study on circulating MicroRNAs and risk of myocardial infarction. J Am Coll Cardiol. 2012:60:290-9.

32. Yokoyama Y, Otsuka K, Kawakami N, Kobayashi S, Ogawa A, Tannno K, et al. Mental health and related factors after the great East Japan earthquake and tsunami. PLoS One. 2014;9:e102497.

33. Yoshimura $\mathrm{E}$, Ishikawa-Takata K, Murakami H, Tsuboyama-Kasaoka N, Tsubota-Utsugi M, Miyachi M, et al. Relationships between social factors and 
physical activity among elderly survivors of the great East Japan earthquake: a cross-sectional study. BMC Geriatr. 2016;16:30.

34. Takahashi S, Yonekura Y, Sasaki R, Yokoyama Y, Tanno K, Sakata K, et al. Weight gain in survivors living in temporary housing in the tsunami-stricken area during the recovery phase following the great East Japan earthquake and tsunami. PLoS One. 2016;11:e0166817.

35. Tsubota-Utsugi M, Yonekura Y, Tanno K, Nozue M, Shimoda H, Nishi N, et al. Association between health risks and frailty in relation to the degree of housing damage among elderly survivors of the great East Japan earthquake. BMC Geriatr. 2018;18:133.

36. Matsuo S, Imai E, Horio M, Yasuda Y, Tomita K, Nitta K, et al. Revised equations for estimated GFR from serum creatinine in Japan. Am J Kidney Dis. 2009;53:982-92

37. Suzuki K, Yamada H, Nagura A, Ohashi K, Ishikawa H, Yamazaki M, et al. Association of cigarette smoking with serum microRNA expression among middle-aged Japanese adults. Fujita Medical Journal. 2016;2:1-5.

38. Alhasan AH, Scott AW, Wu JJ, Feng G, Meeks JJ, Thaxton CS, et al. Circulating microRNA signature for the diagnosis of very high-risk prostate cancer. Proc Natl Acad Sci U S A. 2016;113:10655-60.

39. Lin XJ, Chong Y, Guo ZW, Xie C, Yang XJ, Zhang Q, et al. A serum microRNA classifier for early detection of hepatocellular carcinoma: a multicentre, retrospective, longitudinal biomarker identification study with a nested case-control study. Lancet Oncol. 2015;16:804-15.

40. Wang S, Aurora AB, Johnson BA, Qi X, McAnally J, Hill JA, et al. The endothelial-specific microRNA miR-126 governs vascular integrity and angiogenesis. Dev Cell. 2008;15:261-71.

41. Fichtlscherer S, De Rosa S, Fox H, Schwietz T, Fischer A, Liebetrau C, et al. Circulating microRNA in patients with coronary artery disease. Circ Res. 2010;107:677-84.

42. Fish JE, Santoro MM, Morton SU, Yu S, Yeh RF, Wythe JD, et al. miR-126 regulates angiogenic signaling and vascular integrity. Dev Cell. 2008;15:272-84.

43. Harris TA, Yamakuchi M, Ferlito M, Mendell JT, Lowenstein CJ. MicroRNA-126 regulates endothelial expression of vascular cell adhesion molecule 1. Proc Natl Acad Sci U S A. 2008;105:1516-21.

44. Togliatto G, Trombetta A, Dentelli P, Gallo S, Rosso A, Cotogni P, et al. Unacylated ghrelin induces oxidative stress resistance in a glucose intolerance and peripheral artery disease mouse model by restoring endothelial cell miR-126 expression. Diabetes. 2015;64:1370-82.

45. Haneklaus M, Gerlic M, O'Neill LA, Masters SL. miR-223: infection, inflammation and cancer. J Intern Med. 2013;274:215-26.

46. M'baya-Moutoula E, Marchand A, Six I, Bahrar N, Celic T, Mougenot N, et al. Inhibition of miR-223 expression using a sponge strategy decreases restenosis in rat injured carotids. Curr Vasc Pharmacol. 2019. https://doi.org/ 10.2174/1570161117666190705141152.

47. Taïbi F, Metzinger-Le Meuth V, M'Baya-Moutoula E, Ms D, Louvet L, Bugnicourt JM, et al. Possible involvement of microRNAs in vascular damage in experimental chronic kidney disease. Biochim Biophys Acta. 2014;1842:88-98

48. Jia CY, Li HH, Zhu XC, Dong YW, Fu D, Zhao QL, et al. MiR-223 suppresses cell proliferation by targeting IGF-1R. PLoS One. 2011;6:e27008. https://doi. org/10.1371/journal.pone.0027008.

49. Song L, Duan P, Guo P, Li D, Li S, Xu Y, et al. Downregulation of miR-223 and miR-153 mediates mechanical strech-stimulated proliferation of venous smooth muscle cells via activation of the insulin-like growth factor-1 receptor. Arch Biochem Biophys. 2012;528:204-11.

50. Fiori ME, Barbini C, Haas TL, Marroncelli N, Patrizii M, Biffoni M, et al. Antitumor effect of miR-197 targeting in p53 wild-type lung cancer. Cell Death Differ. 2014;21:774-82.

51. Weber F, Teresi RE, Broelsch CE, Frilling A, Eng C. A limited set of human MicroRNA is deregulated in follicular thyroid carcinoma. J Clin Endocrinol Metab. 2006;91:3584-91.

52. Zou D, Wang D, Li R, Tang Y, Yuan L, Long X, et al. MiR-197 induces Taxol resistance in human ovarian cancer cells by regulating NLK. Tumour Biol. 2015;36:6725-32

53. Willeit P, Zampetaki A, Dudek K, Kaudewitz D, King A, Kirkby NS, et al. Circulating microRNAs as novel biomarkers for platelet activation. Circ Res. 2013;112:595-600

\section{Publisher's Note}

Springer Nature remains neutral with regard to jurisdictional claims in published maps and institutional affiliations.

\section{Ready to submit your research? Choose BMC and benefit from}

- fast, convenient online submission

- thorough peer review by experienced researchers in your field

- rapid publication on acceptance

- support for research data, including large and complex data types

- gold Open Access which fosters wider collaboration and increased citations

- maximum visibility for your research: over $100 \mathrm{M}$ website views per year

At $\mathrm{BMC}$, research is always in progress.

Learn more biomedcentral.com/submissions 